\title{
Celiac plexus block: an anatomical study and simulation using computed tomography ${ }^{*}$
}

\author{
Bloqueio do plexo celíaco: estudo anatômico e simulação em tomografia computadorizada
}

\section{Gabriela Augusta Mateus Pereira ${ }^{1}$, Paulo Tadeu Campos Lopes ${ }^{2}$, Ana Maria Pujol Vieira dos Santos ${ }^{2}$, Adriane Pozzobon ${ }^{3}$, Rodrigo Dias Duarte ${ }^{4}$, Alexandre da Silveira Cima ${ }^{5}$, Ângela Massignan ${ }^{5}$}

Pereira GAM, Lopes PTC, Santos AMPV, Pozzobon A, Duarte RD, Cima AS, Massignan A. Celiac plexus block: an anatomical study and simulation using computed tomography. Radiol Bras. 2014 Set/Out;47(5):283-287.

Abstract Objective: To analyze anatomical variations associated with celiac plexus complex by means of computed tomography simulation, assessing the risk for organ injury as the transcrural technique is utilized.

Materials and Methods: One hundred eight transaxial computed tomography images of abdomen were analyzed. The aortic-vertebral, celiac trunk (CeT)-vertebral, CeT-aortic and celiac-aortic-vertebral topographical relationships were recorded. Two needle insertion pathways were drawn on each of the images, at right and left, $9 \mathrm{~cm}$ and $4.5 \mathrm{~cm}$ away from the midline. Transfixed vital organs and gender-related associations were recorded.

Results: Aortic-vertebral - 45.37\% at left and 54.62\% in the middle; CeT-vertebral -T12, 36.11\%; T12-L1, 32.4\%; L1, 27.77\%; T11T12, 2.77\%; CeT-aortic - 53.7\% at left and 46.3\% in the middle; celiac-aortic-vertebral - L-I, 22.22\%; M-m, 23.15\%; L-m, 31.48\%; M-I, 23.15\%. Neither correspondence on the right side nor significant gender-related associations were observed.

Conclusion: Considering the wide range of abdominal anatomical variations and the characteristics of needle insertion pathways, celiac plexus block should not be standardized. Imaging should be performed prior to the procedure in order to reduce the risks for injuries or for negative outcomes to patients. Gender-related anatomical variations involved in celiac plexus block should be more deeply investigated, since few studies have addressed the subject.

Keywords: Celiac plexus block; Transcrural pathway; Computed tomography; Anatomy.

Resu mo Objetivo: Analisar variações anatômicas relacionadas ao bloqueio do plexo celíaco por meio da simulação por tomografia computadorizada e avaliar a possibilidade de transfixação de órgãos pelo método transcrural.

Materiais e Métodos: Cento e oito imagens de tomografias computadorizadas transaxiais abdominais foram analisadas. As relações aorto-vertebral, tronco celíaco (TCe)-vertebral, TCe-aórtica e celíaco-aorto-vertebral foram registradas. Em cada imagem foram dispostas duas trajetórias de agulhas, a $9 \mathrm{~cm}$ e a $4,5 \mathrm{~cm}$ à esquerda e à direita da linha média. Os órgãos vitais transfixados e associações relacionadas ao gênero foram registrados.

Resultados: Aorto-vertebral - 45,37\% esquerda e 54,62\% central; TCe-vertebral - T12, 36,11\%; T12-L1, 32,4\%; L1, 27,77\%; T11T12, 2,77\%; TCe-aórtica - 53,7\% esquerda e 46,3\% central; celíaco-aorto-vertebral - L-I, 22,22\%; M-m, 23,15\%; L-m, 31,48\%; M-I, 23,15\%. Em nenhum dos critérios analisados houve correspondência no lado direito e nem associação significativa entre os gêneros. Conclusão: 0 bloqueio do plexo celíaco não deve ser padronizado, em razão das amplas variações anatômicas abdominais e das características próprias de cada acesso, sendo necessário o registro de imagem prévio ao procedimento para cada paciente, visando diminuir riscos de lesão. Registros sobre a variação anatômica quanto ao gênero, relacionados ao bloqueio do plexo celíaco, devem ser aprofundados.

Unitermos: Bloqueio do plexo celíaco; Acesso transcrural; Tomografia computadorizada; Anatomia.

* Study developed at Universidade Luterana do Brasil (Ulbra), Canoas, RS, Brazil.

1. MSc, Human Anatomy Professor, Universidade Luterana do Brasil (Ulbra), Canoas, RS, Brazil.

2. PhDs, Human Anatomy Professors, Universidade Luterana do Brasil (Ulbra), Canoas, RS, Brazil.

3. PhD, Human Anatomy Professor, Centro Universitário Univates, Lajeado, RS, Brazil.

4. MD, Radiologist, Fundação Serdil/Saint Pastous, Porto Alegre, RS, Brazil.

5. MDs, Undergraduates, Specialization Program, Radiology and Imaging Diagnosis, Fundação Serdil/Saint Pastous, Porto Alegre, RS, Brazil.

Mailing Address: Dr. Paulo Tadeu Campos Lopes. Universidade Luterana do Brasil. Avenida Farroupilha, 8001, prédio 14, sala 323, Bairro São José. Canoas, RS, Brazil, 92425-900. E-mail: pclopes@ulbra.br.

Received August 12, 2013. Accepted after revision March 10, 2014.

\section{INTRODUCTION}

Celiac plexus block (CPB) is prescribed in cases of upper abdomen cancer, chronic pancreatitis, metastases, painful retroperitoneal tumors and chronic abdominal pain in patients who do not respond to treatment regimens based on high-dose narcotic analgesia ${ }^{(1-3)}$. Since the beginning of the 20th century, the CPB technique has been adapted, giving rise to a variety of techniques that differ mainly in the type of access, the instruments used, sedation, neurolytic solutions, imaging guidance and timing in the course of the disease. The variations and combinations of techniques stand 
as a means to increase the chances of success in the procedure as well as to reduce the occurrence of complications and morbidity ${ }^{(4-8)}$.

The celiac plexus (CP) is deeply located in the retroperitoneum, overlying the anterolateral surface of the aorta, at the level of the celiac trunk (CeT), comprising a dense network of ganglia that varies considerably in size, number and positioning ${ }^{(6-13)}$. It originates from sympathetic fibers of splanchnic nerves, extending from $\mathrm{T} 5$ to $\mathrm{T} 12$, and containing preganglionic splanchnic afferent fibers, preganglionic parasympathetic fibers and postganglionic sympathetic fibers. The CP is found in the epigastrium, posteriorly to the stomach and the pancreas, and anteriorly to the diaphragmatic pillars, where it surrounds the $\mathrm{CeT}$, the superior mesenteric arteries and the aorta. The visceral pain transmitted by the $\mathrm{CP}$ is related to the pancreas, diaphragm, stomach, liver, spleen, small bowel, transverse colon, suprarenal glands, kidneys, abdominal aorta and mesenterium ${ }^{(7,13,14)}$.

The retrocrural, transcrural, transaortic and anterior approaches are the most commonly utilized in CPB, differing from each other in needle directioning, insertion angulation and pathway, as well as in patient positioning, among other factors that involve risks and benefits peculiar to each technique. In CPB, the imaging guidance utilized to visualize the correct insertion of the needle and to confirm contrast medium spread is most commonly done with either computed tomography (CT), ultrasonography or fluoroscopy $^{(6-8,12,15-18)}$. The decision on which individual technique to adopt should be based on the available facilities, clinical expertise, the patients' physical condition, and on the disease severity ${ }^{(18)}$.

CPB may pose risks to the patient, depending on the technique employed and on abdominal anatomical variations ${ }^{(19)}$. Although complications have been recorded in less than $2 \%$ of patients submitted to CPB, diaphragmatic irritation, orthostatic hypotension, pneumothorax, pericarditis, intervertebral disc injury, retroperitoneal abscess, transient diarrhea, artery dissection, pleuritis and neurologic damage have been reported ${ }^{(8,17)}$. In spite of that, reports in the literature confirm the significant benefits to the quality of life of patients who undergo this procedure ${ }^{(4,17,18,20,21)}$.

The variation in CPB techniques adopted since $1919^{(3)}$ and the scarcity of studies reporting problems after this procedure such as organ transfixion and neurologic injury, or even discussing the anatomical variations of structures involved in CPB unveil the need for further information regarding this relevant analgesic resource.

The present study was aimed at analyzing the anatomical variations of structures involved in CPB and implementing one of the techniques described in the literature by means of simulations utilizing CT. Axial CT sections of the abdomen of adult patients were analyzed to assess one of the main risks involved in this procedure, i.e., injury to organs or structures caused by the needle insertion towards the CP region.

\section{MATERIALS AND METHODS}

Transaxial contrast-enhanced abdominal CT images (one-centimeter-thick slices) of 108 adult patients ( 72 women and 36 men), recovered from the Siemens Syngo ${ }^{\circledR}$ system were analyzed. The CPB simulation was based on an adapted version of the transcrural method ${ }^{(22)}$.

For each patient, an axial section at the level of the CeT was utilized to assess the aorta in the craniocaudal direction, from the diaphragm aortic hiatus to the first anterior branch of the abdominal aorta. The celiac trunk was identified according to the following criteria: 1) the first anterior branch of the abdominal aorta; 2) divided into left gastric artery, common hepatic artery, and splenic artery; 3 ) different from the superior mesenteric artery.

The location of the aorta was determined in relation to the vertebral body at the level of the CeT emergence, and defined as follows: anterior to the left third (I); anterior to the middle third $(\mathrm{m})$; and anterior to the right third $(\mathrm{r})$ of the vertebral body.

The site of CeT emergence was determined in relation to the vertebral column. As the axial CT sections were analyzed in the craniocaudal direction, the CeT origin was identified taking the aorta as a reference, at the level of either a vertebral body or an intervertebral space, and recorded as follows: at left $(\mathrm{L})$; at the middle $(\mathrm{M})$; at right $(\mathrm{R})$ of the aortic wall. The celiac-aortic-vertebral topographic relationship was analyzed and divided into the groups L-1, M-m, L-m or M-l, L-r and R-l,

Lines representing the needles pathway were drawn on the axial image where the CeT origin was identified. From the midline defined as the vertebral spinous process, two lines were drawn on each side of the vertebral body. The original image was rotated $180^{\circ}$ so as to simulate the prone position of a patient during the virtual procedure. The first line (L9) was drawn starting $9 \mathrm{~cm}$ away from the midline on the skin surface, tangentially to the vertebral body and crossing the diaphragmatic pillars. The second line was drawn accordingly, though $4.5 \mathrm{~cm}$ away from the midline (L4.5). The vital organs transfixed by L9 and L4.5 as well as the correlation between patients' gender and the analyzed criteria were recorded.

Descriptive statistics were utilized in the data analysis and the data are expressed as means \pm standard deviation. The CeT emergence sites and their topographic relationships are presented as percent values. The exact Fisher test was used to analyze the association between patients' gender, CeT emergence site and topographic relationships. The software Bioestat $5.00^{\circledR}$ was utilized in the statistical analysis, considering 0.05 as significance level $(p \leq 0.05)$.

\section{RESULTS}

In the present study, CT images of 108 individuals, 72 women and 36 men, were analyzed. Most patients presented normal CT findings. In the cases where alterations were detected, the following conditions were most commonly 
diagnosed: renal cyst $(12.03 \%, n=13)$; renal lithiasis $(8.33 \%, n=9)$; hepatic cyst $(5.55 \% \%, n=6)$; liver metastasis $(4.6 \%, n=5)$; colon diverticula $(3.7 \%, n=4)$; hepatic nodules $(2.77 \%, n=3)$; and retroperitoneal lymph node enlargement $(2.77 \%, n=3)$. Renal carcinoma and hepatocellular carcinoma were also diagnosed.

As regards CeT emergence site in relation to the vertebra, in $36.11 \%$ of the cases it emerged at the level of T12; in $32.4 \%$, between $\mathrm{T} 12$ and $\mathrm{L} 1$; in $27.77 \%$, at the level of $\mathrm{L} 1$; and only in $2.77 \%$, between $\mathrm{T} 11$ and $\mathrm{T} 12$.

The results regarding celiac-aortic-vertebral topographic relationship showed correspondence at the left aortic wall (L-l) in $22.22 \%$ of cases, at the middle (M-m) in $23.15 \%$, at the left-middle (L-m) in $31.48 \%$, and central-left $(\mathrm{M}-\mathrm{l})$ in $23.15 \%$ of cases. No correspondence at the right side of the aortic wall was observed.

The percentages of organs transfixed by lines L9 and L4.5 are demonstrated on Table 1. Table 2 shows the results regarding organ transfixion by L9 and L4.5 describing a needle's pathway observed in the present study and in the study developed by Yang et al. ${ }^{(22)}$. Images of some transfixed organs are shown on Figure 1.

No significant correlation was observed between genders and celiac-vertebral, aortic-vertebral, celiac-aortic and celiac-aortic-vertebral topographic relationships.

\section{DISCUSSION}

Scarce information is found in the literature on the radiographic anatomy of structures involved in CPB. The anatomical variations in the $\mathrm{CeT}$ and adjacent structures in the

Table 1-Occurrence of organs and structures transfixion by needle insertion lines L9 and L4.5.

\begin{tabular}{lcccccc}
\hline & \multicolumn{2}{c}{ L9 } & & \multicolumn{2}{c}{ L4.5 } \\
\cline { 2 - 3 } \cline { 5 - 6 } Organs and structures & Right side & Left side & & Right side & Left side \\
\hline Liver & $12.03 \%$ & - & & $8.33 \%$ & - \\
Kidneys & $19.44 \%$ & $23.15 \%$ & & $0.92 \%$ & $0.92 \%$ \\
Spleen & - & $4.62 \%$ & & - & $0.92 \%$ \\
Aorta & $68.51 \%$ & $97.22 \%$ & & $2.7 \%$ & $78.7 \%$ \\
Inferior vena cava & - & - & & $25 \%$ & $0.92 \%$ \\
Portal vein & - & - & & - & $0.92 \%$ \\
Lungs & $67.59 \%$ & $51.85 \%$ & & $54.62 \%$ & $44.44 \%$ \\
Tumor mass & $1.85 \%$ & - & & $1.85 \%$ & $0.92 \%$ \\
\hline
\end{tabular}

L9, line $9 \mathrm{~cm}$; L4.5, line $4.5 \mathrm{~cm}$.
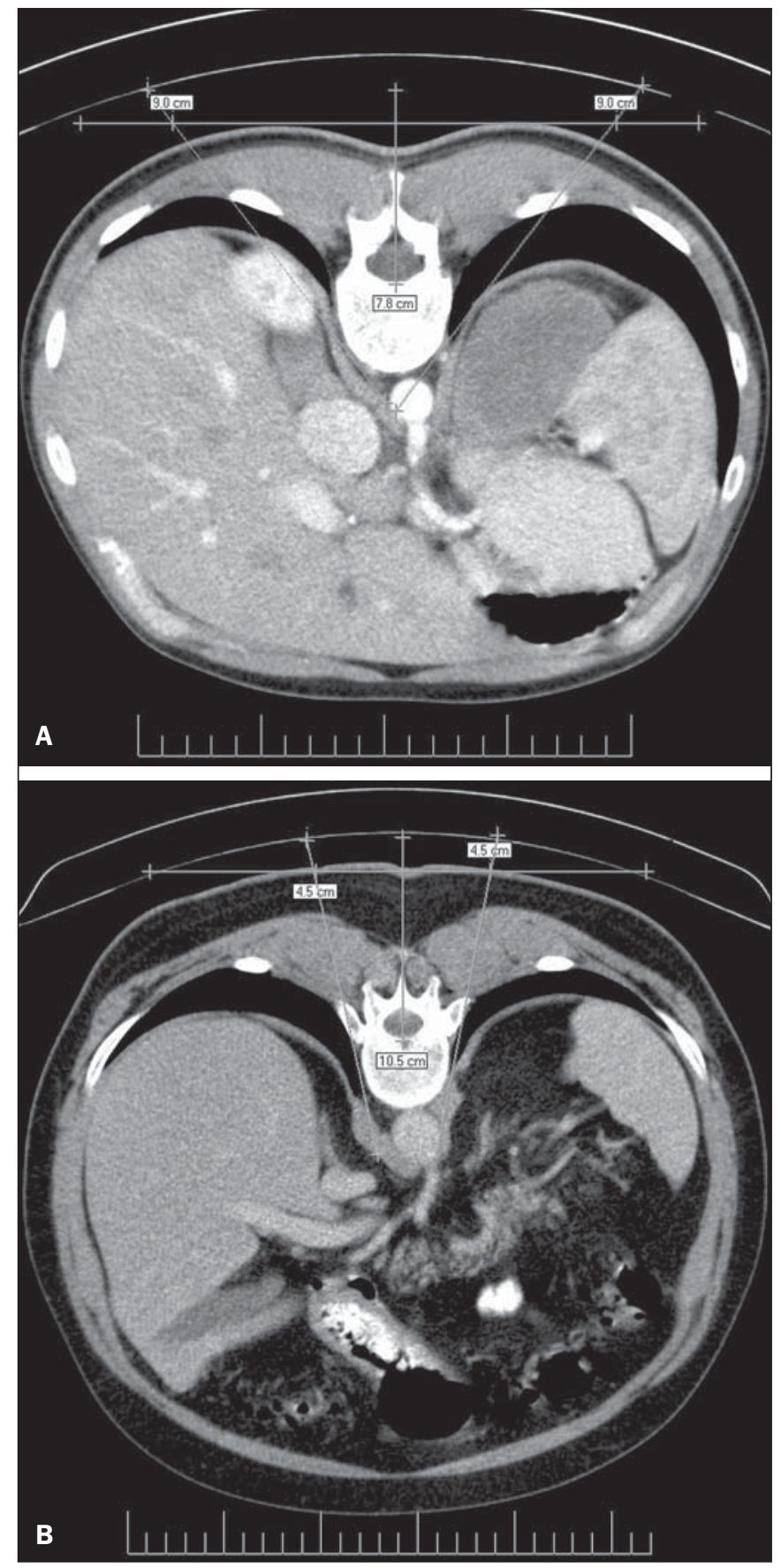

Figure 1. A: Needle insertion pathway $9.0 \mathrm{~cm}$ to the right of the midline, indicating transfixion of lungs. B: Needle insertion pathway $4.5 \mathrm{~cm}$ to the right and to the left of midline, indicating transfixion of lungs.

Table 2-Organs transfixion by the two needle insertion pathways, L9 and L4.5, observed in the present study and in the study developed by Yang et al.(22).

\begin{tabular}{|c|c|c|c|c|c|c|c|c|}
\hline \multirow[b]{2}{*}{ Organ } & \multicolumn{4}{|c|}{ Present study } & \multicolumn{4}{|c|}{ Yang et al. ${ }^{(22)}$} \\
\hline & Right side & Left side & Right side & Left side & Right side & Left side & Right side & Left side \\
\hline Kidneys & $19.44 \%$ & $23.15 \%$ & $0.92 \%$ & $0.92 \%$ & $58 \%$ & $64 \%$ & $4 \%$ & $4 \%$ \\
\hline Aorta & $68.51 \%$ & $97.22 \%$ & $2.7 \%$ & $78.7 \%$ & $68 \%$ & $90 \%$ & $10 \%$ & $84 \%$ \\
\hline Inferior vena cava & - & - & $25 \%$ & $0.92 \%$ & $4 \%$ & $6 \%$ & $48 \%$ & - \\
\hline
\end{tabular}

L9, line $9 \mathrm{~cm}$; L4.5, line $4.5 \mathrm{~cm}$. 
abdomen, which play an essential role in the guidance of the needle during block procedures have not been duly investigated $^{(5,22)}$.

As regards the celiac-aortic-vertebral topographic relationship, Yang et al. have reported twice as many cases as compared with the present study, particularly for the L-I group $^{(22)}$. The present results do not reveal any correlation on the right side, which is corroborated by the low frequency reported in the mentioned study $(0.5 \%$ for both L-r and R-l).

The data of the present study regarding the site of CeT emergence from the aorta are similar to those reported by Yang et al. ${ }^{(22)}$. On the other hand, as regards celiac-vertebral topographic relationship, Yang et al. have observed CeT emergence site between T11-and T12 in $6.5 \%$ of cases, as compared with only $2.77 \%$ observed in the present study.

Data about gender-related associations reported by Puelma et al. ${ }^{(23)}$ demonstrate correlation with T12 in 50\% of male and in $52,9 \%$ of the female patients, and with $\mathrm{L} 1$ in $50 \%$ and $47.1 \%$ respectively.

A significant difference in the aortic-vertebral topographic relationship was observed as the data from de present study are compared with those reported by Yang et al. ${ }^{(22)}$, who reported $70 \%$ anterior to the left third, $29 \%$ anterior to the middle third, and $1 \%$ anterior to the right third of the vertebral body.

The risk for organ injury by needles in CPB according to two lines drawn from the midline was analyzed. In the present study, the right and left lungs were transfixed by the needle pathways corresponding to both lines (Figure 1), while the results reported by Yang et al. ${ }^{(22)}$ did not reveal any possibility of pneumothorax. Additionally, results regarding injury to kidneys, inferior vena cava, aorta and liver were also very different from those reported by the mentioned study (Table 2). Such differences observed between the two studies clearly reveal the key role played by anatomical variations in CPB.

Kidney transfixion is most likely to occur as the needles are inserted $<7.5 \mathrm{~cm}$ away from the midline and as they run laterally to the vertebral body ${ }^{(6)}$. Injury to the pancreas, stomach and liver as well as pneumothorax are rarely reported in the literature ${ }^{(5,7,17,24,25)}$. Injury to kidneys and lungs, for example, has never exceeded $0.8 \%{ }^{(24)}$. The imaging guidance with CT may minimize the occurrence of such complications $^{(6)}$.

In an effort to simulate new needle pathways to the $\mathrm{CP}$ to avoid organs injury, $7.5 \%$ of the 400 simulations on images were excluded from the study because of the occurrence of organ transfixion ${ }^{(26)}$. The same study reported difference in the distance between the site where needles were inserted and the midline (IP-ML) in men and women; larger distances were observed in men. Significant differences were also observed between the right side $(7.04 \mathrm{~cm})$ and the left side $(3.58 \mathrm{~cm}$ ) for this criterion. A distance of about $7.5 \mathrm{~cm}$ was suggested for both sides, though it might vary between $4 \mathrm{~cm}$ and $10 \mathrm{~cm}^{(27)}$.
The IP-ML distance in male patients with pancreatitis was larger $(7.47 \mathrm{~cm}$ on the right side and 3.78 on the left side), as compared with female patients with the same condition $(6.64 \mathrm{~cm} \text { on the right and } 3.25 \mathrm{~cm} \text { on the left side })^{(22,26)}$. In the present study, the diseases detected on images did not have any influence on anatomical aspects and therefore no change was required in the needle pathway up to the $\mathrm{CP}$.

In the literature approaching $\mathrm{CPB}$, there are scarce data about abdominal anatomical variations in men and women, which has been reported in a study developed by McCartney et al. ${ }^{(5)}$. In the present study, no correlation was observed between gender and CeT-vertebral, aortic-vertebral, CeTaortic and celiac-aortic-vertebral topographic relationships. Similarly, data previously published on the CeT-vertebral topographic relationship were not significant ${ }^{(23)}$.

There is controversy about the most appropriate imaging method for guidance in $\mathrm{CPB}^{(3,5,6,18)}$. In another study, Yang et al. recommend the use of preprocedural CT images and fluoroscopy during the procedure ${ }^{(28)}$. Other authors understand that CT-guidance is more appropriate both previously and during the procedure, considering that risks are considerably reduced with the use of this method $\operatorname{din}^{(7,8,17,25,29,30)}$.

\section{CONCLUSION}

CPB should not be standardized, considering the wide range of gender-related abdominal anatomical variations, laterality and pathologies, as well as the characteristics of needle insertion pathways. Imaging should be performed prior to the procedure in order to reduce the risks for injuries or for negative outcomes to patients.

Gender-related anatomical variations of structures involved in celiac plexus block should be more deeply investigated, since few studies have addressed the subject.

The present study may contribute for the knowledge on the anatomy of abdominal arteries required in other invasive surgical, diagnostic or therapeutic procedures.

\section{REFERENCES}

1. Gorbitz C, Leavens ME. Alcohol block of the celiac plexus for control of upper abdominal pain caused by cancer and pancreatitis. Technical note. J Neurosurg. 1971;34:575-9.

2. Singler RC. An improved technique for alcohol neurolysis of the celiac plexus. Anesthesiology. 1982;56:137-41.

3. Fugère F, Lewis G. Coeliac plexus block for chronic pain syndromes. Can J Anaesth. 1993;40:954-63.

4. Hastings RH, McKay WR. Treatment of benign chronic abdominal pain with neurolytic celiac plexus block. Anesthesiology. 1991;75: 156-8.

5. McCartney CJL, Chambers WA. Coeliac plexus block. Curr Anaesth Crit Care. 1998;9:318-24.

6. Mercadante S, Nicosia F. Celiac plexus block: a reappraisal. Reg Anesth Pain Med. 1998;23:37-48.

7. Titton RL, Lucey BC, Gervais DA, et al. Celiac plexus block: a palliative tool underused by radiologists. AJR Am J Roentgenol. 2002; 179:633-6.

8. Wang PJ, Shang MY, Qian Z, et al. CT-guided percutaneous neurolytic celiac plexus block technique. Abdom Imaging. 2006;31: $710-8$. 
9. Ward EM, Rorie DK, Nauss LA, et al. The celiac ganglia in man normal anatomic variations. Anesth Analg. 1979;58:461-5.

10. Paz Z, Rosen A. The human celiac ganglion and its splanchnic nerves. Acta Anat (Basel). 1989;136:129-33.

11. Weber JG, Brown DL, Stephens DH, et al. Celiac plexus block. Retrocrural computed tomographic anatomy in patients with and without pancreatic cancer. Reg Anesth. 1996;21:407-13.

12. Rathmell JP, Gallant JM, Brown DL. Computed tomography and the anatomy of celiac plexus block. Reg Anesth Pain Med. 2000;25: $411-6$.

13. Loukas M, Klaassen Z, Merbs W, et al. A review of the thoracic splanchnic nerves and celiac ganglia. Clin Anat. 2010;23:512-22.

14. Erdine S. Celiac ganglion block. Agri. 2005;17:14-22.

15. Boas RA. Sympathetic blocks in clinical practice. Int Anesthesiol Clin. 1978;16:149-82

16. Montero Matamala A, Vidal Lopez F, Aguilar Sanchez JL, et al. Percutaneous anterior approach to the celiac plexus using ultrasound. Br J Anaesth. 1989;62:637-40.

17. Eisenberg E, Car DB, Chalmers TC. Neurolytic celiac plexus block for treatment of cancer pain: a meta-analysis. Anesth Analg. 1995; 80:290-5.

18. Kambadakone A, Thabet A, Gervais DA, et al. CT-guided celiac plexus neurolysis: a review of anatomy, indications, technique, and tips for successful treatment. Radiographics. 2011;31:1599-621.

19. Haaga JR, Kori SH, Eastwood DW, et al. Improved technique for CT-guided celiac ganglia block. AJR Am J Roentgenol. 1984;142: $1201-4$.

20. Wong GY, Schroeder DR, Carns PE, et al. Effect of neurolytic celiac plexus block on pain relief, quality of life, and survival in patients with unresectable pancreatic cancer: a randomized controlled trial. JAMA. 2004;291:1092-9.
21. Erdek MA, Halpert DE, González Fernández M, et al. Assessment of celiac plexus block and neurolysis outcomes and technique in the management of refractory visceral cancer pain. Pain Med. 2010 11:92-100.

22. Yang IY, Oraee S, Viejo C, et al. Computed tomography celiac trunk topography relating to celiac plexus block. Reg Anesth Pain Med. $2011 ; 36: 21-5$.

23. Puelma F, Olave E. Relaciones del origen del tronco celiaco, arterias mesentéricas y renales con la columna vertebral en individuos chilenos. Int J Morphol. 2010;28:1227-34.

24. Davis DD. Incidence of major complications of neurolytic coeliac plexus block. J R Soc Med. 1993;86:264-6.

25. Hol PK, Kvarstein G, Viken O, et al. MRI-guided celiac plexus block J Magn Reson Imaging. 2000;12:562-4.

26. Yang IY, Oraee S, Viejo C, et al. Transcrural celiac plexus block simulates on 200 computed tomography images. Br J Anaesth. $2011 ; 107: 972-7$

27. Moore DC, Bush WH, Burnett LL. Celiac plexus block: a roentgenographic, anatomic study of technique and spread of solution in patients and corpses. Anesth Analg 1981;60:369-79.

28. Yang IY, Oraee S. A modified approach to transcrural celiac plexus block. Reg Anesth Pain Med. 2005;30:303-7.

29. Gress F, Schmitt C, Sherman S, et al. A prospective randomized comparison of endoscopic ultrasound- and computed tomographyguided celiac plexus block for managing chronic pancreatitis pain. Am J Gastroenterol. 1999;94:900-5.

30. Sekhadia M, Chekka K. Standarts of care for celiac plexus neurolysis: radiologic guidance and fellowship training. J Support Oncol 2009;7:89-90. 